\title{
A saúde mental do aluno prejudicada pelos métodos didáticos aplicados no isolamento social: um exame bibliográfico
}

The student's mental health impaired by didactic methods applied in social isolation: a bibliographic examination

La salud mental del alumno afectada por métodos didácticos aplicados en aislamiento social: un examen bibliográfico

Lázaro Saluci Ramos ${ }^{1 *}$, Jucerlane Baiense de Almeida $^{2}$, Daciana Sedano da Silva ${ }^{2}$, Cristiane Barreto Pereira², Fabiula de Carvalho Barreto², Solange Melo Gomes Macêdo², Carmen Lúcia Custódio da Silva², Edson Montebeller Alves Júnior², Fernanda Tamiasso de Oliveira², Andressa da Silva Santiago ${ }^{2}$.

\section{RESUMO}

Objetivo: O objetivo deste exame é atestar dentro da bibliografia já existente os efeitos negativos de uma didática mal desenvolvida e as consequências para a saúde mental do aluno. Revisão bibliográfica: Desde o início da pandemia de Corona Vírus Disease (Covid-19), muitas instituições de ensino públicas e particulares adotaram o sistema de aulas online. O ensino a distância além de deficitário, já que ultrapassa as possibilidades de muitos alunos de classe social mais baixa, não contabiliza os efeitos que pode causar na saúde mental dos discentes. É aferível que não somente o desenvolvimento intelectual está comprometido, mas as dificuldades ocasionadas pela estranheza dos novos hábitos sociais, confronta a habilidade das famílias e as necessidades orgânicas dos seres humanos. O medo de repetir o ano letivo está inserido nas famílias através de uma cultura tóxica, onde não cumprir o programado significa incapacidade mental. A sensibilidade das famílias e da instituição precisam ser despertadas, a fim de garantir a qualidade de vida durante o isolamento social. Considerações finais: Conclui-se, que a manutenção do método de aulas a distância não só colabora para um choque emocional no discente, como também dificulta a relação familiar entre pais e filhos.

Palavras-chave: Saúde mental, Educação e saúde, Pandemia.

\section{ABSTRACT}

Objective: The objective of this exam is to attest within the existing bibliography the negative effects of a poorly developed didactics and the consequences for the student's mental health. Bibliographic review: Since the beginning of the Corona Virus Disease pandemic (Covid-19), many public and private educational institutions have adopted the online class system. Distance learning is not only deficient, since it exceeds the possibilities of many students from a lower social class, it does not account for the effects it can cause on the students' mental health. It is evident that not only intellectual development is compromised, but the difficulties caused by the strangeness of new social habits, confront the ability of families and the organic needs of human beings. The fear of repeating the school year is embedded in families through a toxic culture, where failure to meet the schedule means mental disability. The sensitivity of families and the institution needs to be awakened in order to guarantee the quality of life during social isolation. Final considerations: It is concluded that the maintenance of the distance learning method not only contributes to an emotional shock in the student, but also hinders the family relationship between parents and children.

Key words: Mental health, Education and health, Pandemic.

${ }^{1}$ Universidade Multivix (MULTIVIX), Cachoeiro de Itapemirim - ES. *E-mail: lazaro321123@gmail.com

${ }^{2}$ Faculdade Vale do Cricaré (FVC), São Mateus - ES.

SUBMETIDO EM: 6/2020

ACEITO EM: 7/2020

PUBLICADO EM: 9/2020

REAS/EJCH | Vol.Sup.n.59 | e4237 | DOI: https://doi.org/10.25248/reas.e4237.2020 Página 1 de 8 


\section{RESUMEN}

Objetivo: El objetivo de este examen es atestiguar dentro de la bibliografía existente los efectos negativos de una didáctica poco desarrollada y las consecuencias para la salud mental del estudiante. Revisión bibliográfica: Desde el comienzo de la pandemia de la enfermedad del virus Corona (Covid-19), muchas instituciones educativas públicas y privadas han adoptado el sistema de clases en línea. La educación a distancia no solo es deficiente, ya que excede las posibilidades de muchos estudiantes de una clase social más baja, no tiene en cuenta los efectos que puede causar en la salud mental de los estudiantes. Es evidente que no solo se compromete el desarrollo intelectual, sino que las dificultades causadas por la extrañeza de los nuevos hábitos sociales confrontan la capacidad de las familias y las necesidades orgánicas de los seres humanos. El miedo a repetir el año escolar está arraigado en las familias a través de una cultura tóxica, donde el incumplimiento del horario significa discapacidad mental. Es necesario despertar la sensibilidad de las familias y la institución para garantizar la calidad de vida durante el aislamiento social. Consideraciones finales: Se concluye que el mantenimiento del método de aprendizaje a distancia no solo contribuye a un choque emocional en el estudiante, sino que también dificulta la relación familiar entre padres e hijos.

Key words: Salud mental, Educación y salud, Pandemia.

\section{INTRODUÇÃO}

A educação no Brasil, desde o início do século $X X$ se pauta no método avaliativo para aferir o conhecimento adquirido. Tal método, com o passar do tempo, se transformou em um grande inimigo da educação, já que o objetivo do aluno se tornou obter nota e não o conhecimento. A famosa expressão utilizada "estudar o suficiente para passar" acabou por limitar o desejo pelo conhecimento, bloquear a capacidade do aluno e reduzir o campo de estudo. O método se tornou extremamente padrão, rompendo com os benefícios do progresso e da tecnologia. A escola, por mais que esteja passando por um processo de democratização, não consegue avançar nas táticas de ensino e nas didáticas mais promissoras, que levaram Países como Noruega e Suécia a alcançar os melhores índices da educação mundial (POZZOBON M, et al., 2017).

Muitas didáticas foram apresentadas por pedagogos e psicopedagogos renomados, como Paulo Freire, por exemplo. Apesar de colaborarem indiscutivelmente com 0 aprendizado, pouco se conduziu 0 desenvolvimento e o aprimoramento dessas linhas de estudo. Os cuidados básicos para que o estudo se torne prazeroso e não cansativo, avançam a passos curtos, fazendo com que apenas os alunos que tenham predisposição àquele sistema de ensino, consigam se destacar e absorver o que é ensinado. As individualidades na sala de aula passam batidas, o docente também não recebe o preparo necessário e por isso acaba não propondo o método mais benéfico e embasado nas linhas progressistas (SOUZA AR, 2019).

Os prejuízos de métodos mal desenvolvidos para aplicação das disciplinas, não ocasiona apenas dano no campo intelectual, mas age diretamente no enfraquecimento da saúde mental do aluno. $O$ aluno que não consegue absorver o aprendizado da maneira como se espera, acaba não obtendo margem suficiente de pontos para ter aprovação, o que socialmente se tornou um vexame e uma inadequada maneira de lidar com a falta do conhecimento. A exposição do aluno nos casos de reprovação e a culpabilização indevida apenas do discente, enfraquece o desejo pelo aprendizado e até afasta o aluno da escola. A evasão escolar possui vários agravantes, e a ausência de métodos democráticos e individuais de aplicação do ensino é um deles (DE FREITAS LC, 2014).

Estar devidamente matriculado em uma escola, se tornou comum nas últimas décadas, graças aos projetos de democratização do acesso à educação. $O$ aluno passou a se alimentar melhor, a garantir o mínimo de conhecimento e ter oportunidades que antes eram reservadas apenas aos filhos de pessoas das classes altas e médias. Foi através da educação que muitos brasileiros conseguiram ultrapassar as barreiras das universidades, e dessa forma inspirou todas as famílias a buscarem através da educação uma vida melhor para seus filhos. A cobrança é real, e muitas vezes é benéfica, já que garante que o aluno estará em pleno contato com aquilo que está sendo ensinado, mas as consequências de uma cobrança acintosa e desproporcional é a interferência direta na capacidade mental e no desenvolvimento intelecto-social (LEONARDO NST e SILVA VG, 2013).

REAS/EJCH | Vol.Sup.n.59 | e4237 | DOI: https://doi.org/10.25248/reas.e4237.2020 Página 2 de 8 
Em questão de saúde mental, muito se desenvolveu em discussão nos últimos anos. O aluno acaba sofrendo um impacto maior quando deixa de frequentar o ambiente escolar, tanto pelo julgamento social quanto pela ausência de amparo para desenvolver-se intelectualmente. Estimular as atividades cerebrais é a maneira mais eficaz de garantir uma melhor compreensão nas atividades cotidianas como trabalho, relações familiares e sociais.

A transmissão do conhecimento presencialmente estimula o desenvolvimento social do aluno, já que este terá que dividir o mesmo espaço com outros alunos, que por sua vez garantirão o aprendizado de como se comportar socialmente para respeitar os direitos e liberdades do próximo. Da mesma forma, estimulará o aluno a buscar formas de se relacionar melhor com os demais (BARROS S e CLARO HG, 2011).

Através desta pesquisa, busca-se aprimorar através da bibliografia já existente, os métodos de aplicação da didática educacional para alunos da educação básica brasileira, para que não sintam de maneira negativa os impactos do isolamento social causado pela pandemia de Covid-19. O objetivo central está pautado em utilizar pesquisas científicas e estudos recentes, mas também reunir o que já se tem de conhecimento acerca de saúde mental do aluno a fim de auxiliar nas políticas futuras. O desenvolvimento intelectual está intimamente ligado as condições do ambiente que ele se desenvolve, sendo os resultados mais positivos quando o ambiente é saudável.

\section{REVISÃO BIBLIOGRÁFICA}

A saúde mental é assunto de inúmeras discussões devido aos recentes estudos e ao grande desenvolvimento das ciências psicológicas. No passado, era muito comum utilizar a internação em Manicômios ou clínicas, que por sua vez não estavam dispostas a tratar os pacientes, mas torná-los um problema a menos no lar de suas famílias. Com o passar do tempo, as pesquisas na área neurológica avançaram, e trouxeram soluções das mais simples as mais complexas para inúmeros distúrbios e patologias. As escolas estão presentes na vida da maioria dos brasileiros em início de desenvolvimento intelectual, e por isso passaram a ter foco nos estudos da psicologia e recentemente, grande parte das escolas no Brasil passaram a abrigar profissionais da área com a finalidade de acompanhar o desenvolvimento do aluno (CID MFB, et al., 2019).

A forma como se age no ambiente escolar é objeto de inúmeros estudos com objetivos apontados. É de extrema importância conciliar o objetivo de adquirir o melhor conhecimento através de táticas menos cansativas, custosas e desestimuladoras. Atrair a atenção é como decifrar um enigma, já que nenhum aluno apresenta semelhanças significativas na personalidade, sendo necessário desenvolver métodos que contemplem o máximo possível de individualidades. O resultado de métodos mal desenvolvidos é a baixa aprendizagem e danos ao desenvolvimento escolar, o que pode desencadear uma série de problemas que evoluem do mental para o físico (SILVA GV, et al., 2019).

O baixo envolvimento das famílias no desenvolvimento dos currículos escolares e nas táticas de aplicação da didática, reduziu ainda mais a abrangência de individualidades, já que não se tornou um costume expor as individualidades para que elas possam ser contempladas. A escola, que por sua vez deveria ser um espaço de acolhimento, se tornou o pesadelo de muitos alunos da rede pública nacional, já que a maioria dos seres humanos possuem o instinto de não permanecer em ambientes que prejudiquem seu desenvolvimento, o que faz com que eles se afaste. Uma parcela pequena ainda consegue estimular e cobrar mutações necessárias, mas a grande maioria não consegue reunir conhecimento ou ter espaço para tal (BRUGELMANN H, 2015).

A saúde mental durante a pandemia de Covid-19 se tornou um estudo pertinente, já que é um momento diferente de tudo que já se viveu. $\mathrm{O}$ isolamento social trouxe à tona inúmeras peculiaridades e formas alternativas de manter-se bem, formas que já eram desenvolvidas e praticadas, como os exercícios físicos em casa, a alimentação mais regrada e rica em vitaminas, o controle sobre ambientes que se frequenta e a higiene corporal após se expor a locais desconhecidos. Entretanto, práticas que são absorvidas com mais tranquilidade pelos adultos, soa como uma bomba para crianças e adolescentes que ainda não foram familiarizados com o método do isolamento. A grande maioria das crianças e dos adolescentes, além de deixarem de frequentar o ambiente escolar, estão tendo que lidar com a permanência integral em casa, tendo quase todos os contatos físicos com meios diferentes, castrados (OPAS, 2020). 
A forma como a doença é transmitida e a fácil disseminação dela nos ambientes mais frequentados, faz com que o ser humano tenha que redobrar os cuidados e renovar suas práticas diárias. Todo novo comportamento social deve ser observado para que suas consequências sejam as mais brandas possíveis. Mergulhar no desconhecido é um caminho perigoso, mas no momento em que se faz, é extremamente necessário.

A saúde mental é a principal fonte de observação no momento, já que o inconsciente obtém as mais minuciosas informações de casa novo ato, até mesmo as informações que passam batidas as percepções humanas. O nível de estresse, as crises de ansiedade e o agravamento multilateral de transtornos ocultos, leva a ciência a um outro desafio, que não somente a busca pela cura do Covid-19, mas como preservar a funcionalidade do cérebro e não permitir que 0 isolamento cause transtornos, que por sua vez, podem apresentar consequências piores que a contaminação pelo vírus (SCHMIDT B, et al., 2020).

\section{Comprometimento da saúde do aluno com a inserção brusca da nova didática}

As implicações de uma modificação brusca na didática escolar podem ultrapassar e muito as barreiras da absorção do conhecimento. Não somente a inteiração com a didática fica comprometida, mas a saúde de quem está para absorver e de quem está transmitindo o conhecimento. $O$ cérebro humano está familiarizado com mudanças alterações a longo prazo, e mesmo assim apresenta reações à essas alterações, como por exemplo a alteração do humor e o comportamento em sociedade. É muito comum notar diferença no humor e no comportamento do aluno quando sofre uma mudança brusca no seu cotidiano, a separação dos pais, a mudança de ambiente e até a perda de alguém próximo exemplifica bem o que está sendo discutido. A criança e 0 adolescente, por serem mais suscetíveis, acabam apresentando formas diversas de comportamento (FALKENBERG MB, et al., 2014).

O contato com outros seres humanos é de indispensável valia para desenvolver o contato humano e o senso de compartilhamento de espaço na sociedade. Romper com a política de convivência, principalmente para uma criança e um adolescente, que estão começando a absorver as práticas de convivência, causará sem sombra de dúvidas, um comprometimento no decorrer da vida. É inimaginável um ser humano em plena saúde mental, que não sinta a necessidade de estar em meios povoados, também é difícil de analisar uma vivencia saudável para aquele que não consegue respeitar ou reconhecer o espaço do próximo. Os estudos da sociedade apresentam diagnósticos raros de pessoas que não conseguem ou não desejam se enturmar, tais estudos são tratados como oportunidades escassas para compreender as individualidades humanas (KINKER FS, et al., 2018).

$\mathrm{O}$ ato de retirar o aluno da sala de aula, onde a convivência era constante, e colocá-lo diante de um computador para absorver o conhecimento, faz com que o mesmo não sinta a importância de dividir o conhecimento e desenvolver práticas de convivência mútua. Após o início do isolamento social, muito rapidamente iniciou-se as aulas on-line através de plataformas disponibilizadas pelas escolas. Que tempo tiveram os cientistas sociais e os profissionais da psicologia para apresentar um estudo suficiente que delimitasse regras e táticas para esta nova realidade? Talvez os propositores de tal ideia não tivessem contabilizado a estimativa de tempo que a pandemia fosse durar, e a preocupação com o possível tempo perdido foram colocadas acima dos interesses da saúde dos alunos (SCHMIDT B, et al., 2020).

Pouco foi apontado de como a sociedade reagiria ao isolamento, apenas que ele é necessário para conter a disseminação do vírus, já que o sistema de saúde pública do Brasil já costuma apresentar deficiências fora de momentos tão importantes como este. Mas retirar o foco das consequências que as novidades trazem para não permitir que um ano letivo seja perdido, é como reduzir a importância de algo que pode causar muito mais danos que a disseminação do contágio. Lidar com o estresse e com as variações de convivências ainda é uma atividade para uma criança, a adaptação requer movimentos leves e menos impactantes possíveis.

A falta de um ambiente de troca de experiências, a redução do convívio social e a limitação do espaço físico os impúberes estão sendo submetidos, já é uma carga de informação altíssima. Introduzir Ihes a responsabilidade de garantir notas ou aprovação nas disciplinas, é um estresse a mais, que não estava programado ou sendo esperado (ZANON C, et al., 2020). 
Confundir desenvolvimento com responsabilidade pode tornar-se uma violência contra a criança e o adolescente. Além da sociedade que julga e aponta erros constantemente, a família que se sente pressionada pelos apontamentos acaba participando de tal violência. Moldar o ser humano como uma máquina de produção, ultrapassa qualquer barreira da desumanidade, já que obter prazer é indispensável para boa formação intelectual e social (ABRANCHES CD e ASSIS SG, 2011).

Para Schmidt B, et al. (2020), não seria necessário romper com as táticas de aprendizado para não introduzir novas preocupações e possíveis consequências negativas na vida da criança, mas potencializar que os novos conhecimentos das novas formas de comportamento e convívio, sejam contabilizados como conhecimento adquirido enquanto a pandemia durar.

É compreensível que novas práticas terão que ser maturadas e novos meios de convivência desenvolvidos, até ao menos uma cura formal ou uma prevenção segura sejam desenvolvidas. Entretanto, dosar as responsabilidades para que os novos métodos se tornem um costume não tão nocivo é uma prática mais saudável. A avaliação de profissionais que estudam o comportamento e o cérebro humano, deve ser aguardada, já que até para os mesmos se trata de algo novo e eles devem ter o seu tempo de análise respeitado.

Enquanto não for maturada toda a gleba de demandas científicas na área da saúde mental, não serão possíveis apontamentos seguros de como proceder e progredir em uma sociedade que certamente terá seu comportamento modificado (DE TROI M e QUINTILIO W, 2020).

\section{Impactos negativos a saúde mental e a construção do ambiente saudável}

A saúde mental foi colocada extremamente a prova durante a pandemia de Covid-19. Inúmeros impactos inesperados já apresentaram sua face ou ainda vão apresentar no decorrer do tempo. Uma mudança tão brusca e repentina não poderia agir de outra forma, já que em constante formação e complexidades as quais se enquadra o cérebro humano adulto e que produz uma série de efeitos, é compreensível que na criança e no adolescente, que ainda não apresentaram sua formação cerebral por completo, esses efeitos sejam mais graves e complexos (MEDEIROS EAS, 2020).

Todas as epidemias têm um forte impacto social, econômico e político. Lembre-se, por exemplo, em Portugal, a pandemia de influenza de 1918-1919 foi chamada de "Pneumônica". Os fatos provaram que este é um dos incidentes mais mortais e um terço da população mundial é afetada, o equivalente a cerca de 500 milhões de pessoas. (MAIA BR e DIAS PC, 2020).

Para que um ambiente mais saudável possível seja construído evitando que a mente dos alunos adoeçam e se torne mais um problema a ser tratado, é necessária uma análise profunda dos riscos que a sobrecarga traz e como que novas técnicas inseridas de maneira precoce, sem estudos suficientes comprovando a sua eficiência, podem prejudicar o discente. O ambiente familiar, apesar de deficitário no Brasil, busca se adaptar juntamente com seus membros, em uníssono, e nem sempre a técnica favorece, já que muitos ambientes já eram doentes antes mesmo do isolamento social (MAIA BR e DIAS PC, 2020).

Embora estejamos experimentando o impacto inicial da pandemia, à luz do que já aconteceu nos países europeus, as discussões sobre o quadro de segurança alimentar brasileira e suas interfaces são muito urgentes. Existem muitas incertezas no setor de alimentos, seja na produção, distribuição, comercialização ou preparação das famílias, há poucas orientações sobre esse assunto. Para que o ambiente se torne saudável ou retorne à normalidade, é preciso também que as necessidades básicas das pessoas sejam resguardadas e promovidas. A função do Estado também é garantir a sobrevivência em estados de exceção, assim, promover a alimentação saudável é uma forma de construir um ambiente mais saudável (OLIVEIRA TC, et al., 2020).

Até agora, as pessoas pensam que há um desacordo entre as áreas de poder relacionadas à tomada de decisão. Fundações, conselhos, universidades públicas e associações produziram materiais educacionais, cujo escopo é desconhecido. Essa situação é complexa e dinâmica e exigirá que o governo, o setor privado e a ação pública combatam o COVID-19, considerando todos os aspectos da insegurança alimentar (OLIVEIRA TC, et al., 2020). 


\section{O comprometimento do convívio familiar}

Historicamente, as famílias distribuíram entre seus membros as responsabilidades do cotidiano. Com o passar dos anos e dando-se os benefícios do progresso, as funções de cada membro variaram, e muitas alterações foram possíveis graças a conquistas de direitos sociais e individuais. A mulher não mais é obrigada a ser a cuidadora do lar, apesar que na grande maioria dos lares são elas as responsáveis pelos afazeres domésticos e o homem responsável por prover o recurso financeiro. Os filhos já não mais são obrigados a trabalhar em tenra idade para colaborar com as despesas, até porque, está disposto em lei o direito a educação, que confere a todas as crianças e adolescentes a obrigação de frequentar um ambiente escolar (MOREIRA MIC, et al., 2011).

O convívio dentro de um lar, seja ele estruturado da maneira como for, depende da sensibilidade de todos os membros e das condições estruturais, sejam elas físicas ou psicossociais. A rotina acaba por gerar vícios, o que causa estranheza quando este ciclo é interrompido ou modificado por qualquer motivo que seja. As consequências pela interrupção de um ciclo, por mais que possa parecer óbvia, é sempre uma incógnita. As reações podem variar, desde a alteração de humor, até doenças mais graves.

Uma pessoa idosa que trabalhou durante cinquenta ou sessenta anos, certamente sentirá alterações no seu corpo físico se parar de exercer as mesmas atividades rotineiras. Por vezes, a perda dos objetivos e o bloqueio na capacidade de almejar algo, também pode influenciar nos desdobramentos futuros de um ser humano (CHERMAN A e DA ROCHA-PINTO SR, 2016).

O comportamento das famílias diante de um acontecimento que muda toda sua rotina, é potencialmente inesperado. É dessa maneira que a mudança de hábitos está acontecendo dentro dos lares durante a pandemia de Covid-19 no Brasil e no Mundo.

Além da fragilização das estruturas construídas pelo convívio, as alterações causam um aumento de responsabilidades que por ora era desconhecida. Para as famílias em que todos os membros estão isolados dentro do lar, a sensação de segurança e proteção nem sempre é suficiente para abonar a ausência de convívio social. As crises financeiras e a ausência de insumos para a manutenção da vida, está colaborando para o aumento do estresse e consequentemente expondo os pontos fracos de lares que nunca apresentaram problemas (BEZERRA AVC, et al., 2020).

Para muitas famílias, as responsabilidades e ações de controle do lar aumentaram. Principalmente para aquelas que mantiveram seus afazeres fora de casa e tiveram que lidar com as responsabilidades dos filhos. Além do aumento dos cuidados e dos gastos, o momento de descanso pode ter se tornado uma extensão da escola dos filhos para os genitores ou responsáveis. A prática escolar falha no construir alunos autodidatas, que consequentemente dependem do auxílio de um tutor, papel exercido pelo professor. Os pais, quando não profissionais da educação ou da pedagogia, não foram preparados para tal demanda, e mesmo que sejam da área, necessitam de momentos livres para realizar outros afazeres (BEZERRA AVC, et al., 2020).

A perda do equilíbrio mental pode potencializar ações tóxicas familiares. O aumento do sofrimento de crianças, adolescentes e mulheres que são vítimas de violência doméstica, certamente é um agravante para o desequilíbrio dos lares durante a pandemia de Covid-19.

Além da cultura do não denunciar, as vítimas são assoladas por inúmeros medos, como: não ser capaz de suprir a ausência de recursos, da violência se agravar e da pressão causada por ameaças de mais violência e morte. A criança e o adolescente, por sua vez, além de ter suas responsabilidades escolares potencializadas, dependem dos cuidados certos para que o ambiente não se torne uma armadilha, como a potencialização dos riscos de doenças mentais, transtornos psicológicos e até a construção de hábitos nocivos a sociedade (MARQUES ES, et al., 2020).

As crises familiares acabam por serem agravadas sempre que algo foge a rotina e a monotonia. Isso expõe o completo despreparo dos entes familiares nas conduções dos seus lares, e a face crítica do capitalismo. Os seres humanos estão fadados a dedicar seu tempo quase que exclusivo ao trabalho, e muito pouco a saúde do lar. O tempo para o convívio é sempre cerceado pelas necessidades físicas de descanso e outras atividades domésticas que não podem ser transferidas. 
O brasileiro que trabalha na média 44 horas por semana, segundo o Instituto Brasileiro de Geografia e Estatística (IBGE, 2015), fica absolutamente comprometido com o aumento de qualquer responsabilidade que possa acontecer. A média de horas que podem ser dedicadas aos entes próximos e ao fortalecimento do convício gira em torno de 4 horas por dia, o que obviamente não é suficiente, considerando todas as demandas de um ambiente saudável (JUNIOR EG, et al., 2013).

\section{CONSIDERAÇÕES FINAIS}

Compreende-se, portanto, que novas práticas e necessidades se instalaram nos lares durante 0 isolamento social, e a sensibilidade com a sobrecarga na mente das crianças e adolescentes está sendo desprezada, quando a prioridade gira em torno da manutenção da máquina capitalista e não dos cuidados necessários para que tudo esteva o mais bem estruturado possível quando o novo ciclo começar. O corte do convívio social já é um baque muito grande e uma mudança extremamente nociva a saúde dos alunos, inserir mais novidades como aulas on-line e estudos dirigidos via internet, compromete a manutenção dos seus laços familiares além da saúde psicológica. O momento é de se sensibilizar e compreender que atitudes grosseiras mais restritivas, só fazem com que crianças e adolescentes sofram mais com a castração dos seus convívios, e que não vão colaborar para o desenvolvimento intelectual futuro.

\section{REFERÊNCIAS}

1. ABRANCHES CD, ASSIS SG. A (in)visibilidade da violência psicológica na infância e adolescência no contexto familiar. Cadernos de Saúde Pública, 2011; 27(5): 843-854.

2. BARROS S, CLARO HG. Processo ensino aprendizagem em saúde mental: o olhar do aluno sobre reabilitação psicossocial e cidadania. Revista da Escola de Enfermagem da USP, 2011; 45(3): 700-707.

3. BEZERRA AVC, et al. Fatores associados ao comportamento da população durante o isolamento social na pandemia de COVID-19. Ciência \& Saúde Coletiva, 2020; 25(1): 2411-2421.

4. BRUGELMANN H. Didática da Sala de Aula: entre abertura e estruturação. Educação \& Realidade, 2015; 40(2): 349374.

5. CHERMAN A, DA ROCHA-PINTO SR. Valoração do conhecimento nas organizações e sua incorporação nas práticas e rotinas organizacionais. Revista Brasileira de Gestão de Negócios, 2016; 18(61): 416-435.

6. CID MFB, et al. Saúde mental infantil e contexto escolar: as percepções dos educadores. Pro-Posições, 2019; 1(30): $1-24$.

7. DE FREITAS LC. Os reformadores empresariais da educação e a disputa pelo controle do processo pedagógico na escola. Educ. Soc., Campinas, 2014; 129(35): 1085-1114.

8. DE TROI M, QUINTILIO W. Coronavírus: lições anti-negacionistas e o futuro do planeta. SciELO em Perspectiva, 2020; ed on: 1-12.

9. FALKENBERG MB, et al. Educação em saúde e educação na saúde: conceitos e implicações para a saúde coletiva. Ciência \& Saúde Coletiva, 2014; 19(3): 8470852.

10. IBGE. 2015. In: INSTITUTO brasileiro de Geografia e Estatística, Distribuição das pessoas de 10 anos ou mais de idade, ocupadas na semana de referência, por grupos de horas habitualmente trabalhadas por semana em todos os trabalhos - Brasil - 2014-2015. Brasília: brasil em síntese. Disponível em: https://brasilemsintese.ibge.gov.br/trabalho/horas-trabalhadas.html. Acesso em: 29 de jun. 2020.

11. JUNIOR EG, et al. Exigências familiares e do trabalho: um equilíbrio necessário para a saúde de trabalhadores e organizações. Pensando famílias, 2013; 17(1): 110-122.

12. KINKER FS, et al. O desafio da formação permanente no fortalecimento das Redes de Atenção Psicossocial. Interface (comunicação, saúde e educação), 2018; 22(67): 1247-1256.

13. LEONARDO NST, SILVA VG. A relação entre aprendizagem e desenvolvimento na compreensão de professores do Ensino Fundamental. Psicologia Escolar e Educacional, 2013; 17(2): 309-317.

14. MAIA BR, DIAS PC. Ansiedade, depressão e estresse em estudantes universitários: o impacto da COVID-19. Estudos de Psicologia (Campinas), 2020; 37(esp): 1-11.

15. MARQUES ES, et al. A violência contra mulheres, crianças e adolescentes em tempos de pandemia pela COVID-19: panorama, motivações e formas de enfrentamento. Cad. Saúde Pública, 2020; 36(4): 1-6.

16. MEDEIROS EAS. Desafios para o enfrentamento da pandemia Covid-19 em hospitais universitários. Revista Paulista de Pediatria, 2020; 38(esp): 1-3.

17. MOREIRA MIC, et al. A família contemporânea brasileira em contexto de fragilidade social e os novos direitos das crianças: desafios éticos. Psicologia em Revista, 2011; 1(17): 161-180.

18. OLIVEIRA TC, et al. (In)Segurança alimentar no contexto da pandemia por SARS-CoV-2. Cadernos de Saúde Pública, 2020; 36(4): s/p.

19. OPAS. 2020. In: ORGANIZAÇÃO Pan-Americana de Saúde. São Paulo: paho.org. Disponível em: https://www.paho.org/bra/index.php?option=com_content\&view=article\&id=6130:covid-19-materiais-decomunicacao\&Itemid=0\#atividade. Acesso em: 5 de jun. 2020. 
20. POZZOBON M, et al. Renomeando o fracasso escolar. Psicologia Escolar e Educacional, 2017; 21 (3): $387-396$.

21. SCHMIDT B, et al. Saúde mental e intervenções psicológicas diante da pandemia do novo coronavírus (COVID-19). Estudos de Psicologia (Campinas), 2020; 6(37); 1-14.

22. SILVA GV, et al. Promoção de saúde mental para adolescente em uma escola de ensino médio - Um relato de experiência. Revista do NUFEN, 2019; 11(2): 133-148.

23. SOUZA AR. As condições de democratização da gestão da escola pública brasileira. Ensaio: Avaliação e Políticas Públicas em Educação, 2019; 27(103): 271-290.

24. ZANON C, et al. COVID-19: implicações e aplicações da Psicologia Positiva em tempos de pandemia. Estudos de Psicologia (Campinas), 2020; 2(37): 1-11. 